\title{
EL CONFLICTO ENTRE LA EXIGENCIA DE DEMOCRACIA INTERNA Y EL DERECHO DE AUTOORGANIZACIÓN DE LOS PARTIDOS POLÍTICOS: EL CASO YABLOKO RUSSIAN UNITED PARTY AND OTHERS V. RUSSIA (8 DE NOVIEMBRE DE 2016)'
}

The conflict between the demand for internal democracy and the right of self-organization of the political parties: the case Yabloko Russian United Party and others v. Russia (November 8, 2016)

\section{ANDRÉS IVÁN DUEÑAS CASTRILLO \\ Universidad de Valladolid andres.d.castrillo@gmail.com-625411380}

Cómo citar/Citation

Dueñas Castrillo, A. I. (2019)

El conflicto entre la exigencia de democracia interna y el derecho de autoorganización de los partidos políticos: el caso Yabloko Russian United Party and others v. Russia (8 de noviembre de 2016) Revista Española de Derecho Constitucional, 117, 311-330. doi: https://doi.org/10.18042/cepc/redc.117.10

\section{Resumen}

Los partidos políticos son instrumentos fundamentales para la participación política. De un lado, cumplen un papel esencial en la formación de la voluntad del Estado, por lo que se les exige un funcionamiento interno democrático. Del otro, el Estado ha de respetar su autonomía. La sentencia que se analiza en el presente

\footnotetext{
Estudio cofinanciado por el Fondo Social Europeo. Trabajo realizado en el marco del Proyecto de Investigación DER2016-75993-P, sobre «Espańa ante Europa: retos nacionales en materia de derechos humanos", que se desarrolla entre el 30 de diciembre de 2016 y el 29 de diciembre de 2020.
} 
texto resuelve la dialéctica que existe entre ambos principios: la exigencia de democracia interna en los partidos políticos y su derecho de autoorganización.

\title{
Palabras clave
}

Partidos políticos; democracia; elecciones primarias; participación.

\begin{abstract}
Political parties are fundamental instruments for political participation. They play an essential role in the formation of the will of the State. For this reason, they are required to have a democratic internal functioning. However, the State must respect their autonomy. The sentence analyzed resolves the tension between both principles: the requirement of internal democracy in the political parties and their self-organization right.
\end{abstract}

\section{Keywords}

Political parties; democracy; primary elections; participation. 


\section{SUMARIO}

I. INTRODUCCIÓN. II. ANÁLISIS DE LA SENTENCIA: 1. Circunstancias del caso. 2. Argumentos de las partes, fundamentos de derecho y fallo del tribunal. III. LA IMPORTANCIA DE LA DECISIÓN EN EL DEBATE SOBRE LA INTRODUCCIÓN DE PRIMARIAS EN LOS PARTIDOS POLÍTICOS EN ESPAÑA. IV. CONCLUSIONES. BIBLIOGRAFÍA.

\section{INTRODUCCIÓN}

No hay duda de que los partidos políticos juegan un papel fundamental en la actual democracia. Esta no se puede entender sin su concurrencia para el desarrollo de la voluntad del Estado. Es lo propio de un Estado de partidos, como diría García Pelayo (1986), aunque hay quien prefiere hablar de Estado con partidos (Solozábal Echavarría, 2015: 293).

Kelsen fue uno de los primeros y más importantes autores en hacer una defensa de la necesidad de los partidos y la centralidad de su papel en el funcionamiento del Estado constitucional, por lo que la entrada en el ámbito del Derecho positivo era fundamental para evitar las tendencias oligárquicas en su seno:

[...] la inserción constitucional de los partidos políticos crea también la posibilidad de democratizar la formación de la voluntad colectiva dentro de su esfera. Esto es tanto más necesario cuanto que puede suponerse que es precisamente la estructura amorfa de este ámbito lo que da lugar al carácter señaladamente aristocrático-autocrático que tienen los procesos de formación de la voluntad colectiva dentro de los mismos, aun en partidos de programa radicalmente democrático (1934: 45).

Antes otras voces habían apuntado en la dirección contraria:

[...] regular la propia lucha de los partidos no es posible, salvo que se produzca la decadencia de una activa representación popular [...]. El hecho de que los partidos sean creaciones fundadas sobre la libre adscripción impide que sean disciplinados por la ley, la cual puede regular solamente los organismos creados por regulación estatal, y no las creaciones surgidas libremente como organizaciones sobre el campo del actual ordenamiento social (Weber, citado por Blanco Valdés, 1990: 64). 
De las opiniones de Kelsen y Weber se desprende la tensión existente entre la exigencia de democracia interna y su regulación por parte del Estado y la autonomía de los partidos políticos, esto es, su derecho de autoorganización. Efectivamente, este tipo de asociaciones no son órganos del Estado, pero no cabe duda de que cumplen funciones de relevancia pública. Lo anterior ha propiciado que muchas constituciones siguieran a Kelsen e incluyesen en sus textos referencias a los partidos, describiéndolos como instrumentos fundamentales para la participación política, por lo que la exigencia de democracia interna en su seno es imprescindible. Como recuerda De Otto Pardo:

[...] el mandamiento de democracia interna tiene la finalidad de que los actores principales del juego democrático estén organizados y adopten sus decisiones conforme a las reglas democráticas que configuran la organización y actividad del Estado y que el derecho del ciudadano a participar libremente no se desvirtúe cuando se adopte la forma más eficaz de participación, la integración en un partido político (1985: 59).

Pero ¿cómo puede el Estado llevar a cabo este objetivo que indica De Otto? ¿Cuáles son los límites a la hora de desarrollar la exigencia de democracia interna en los partidos? $\mathrm{O}$, visto desde otra perspectiva, ¿qué principios han de respetar los partidos en su derecho de autoorganización? La sentencia que se analiza en este trabajo otorga claridad a estas preguntas. El objetivo de las siguientes líneas es comentar la resolución del caso y sus particularidades, que pueden tener una especial incidencia en el actual debate sobre la inserción de primarias obligatorias en los partidos por vía legislativa para la nominación de candidatos, a lo que se alude en el último epígrafe.

\section{ANÁLISIS DE LA SENTENCIA}

\section{CIRCUNSTANCIAS DEL CASO}

Se debe comenzar explicando que la República de Karelia es una región perteneciente a la Federación Rusa que cuenta con una Asamblea Legislativa elegida directamente por sufragio universal.

El partido político Yabloko, registrado en 2002 ante la autoridad estatal competente, realizó su congreso regional en los días 27 de mayo y 12 de agosto de 2006 para preparar las elecciones a la Asamblea de dicha región, que se celebraban en otoño de 2006. El objetivo de este congreso, entre otros, era la nominación de los candidatos que concurrirían en la lista del partido. 
Los estatutos de Yabloko diferencian entre militantes y militantes registrados. Para tener el derecho de elegir y ser elegido como candidato se ha de ser, según las normas internas del partido, militante registrado. En la primera de las sesiones del congreso, varios de los delegados presentes expresaron su deseo de participar como candidatos en las elecciones regionales a la Asamblea Legislativa de la República de Karelia. El proceso de nominación de candidatos se realizó en la sesión de agosto, a la que acudieron dos miembros de la Dirección de Karelia del Servicio de Registro Federal del Ministerio de Justicia y dos miembros de la Comisión Central Electoral de la República de Karelia, que no reportaron ninguna irregularidad en la conferencia regional del partido.

Finalmente, el partido registra ante la Comisión Electoral de Karelia los documentos — incluida la lista con los candidatos elegidos previamente- en orden a participar en los comicios regionales. Sin embargo, el 31 de agosto de 2006 la Dirección de Karelia del Servicio de Registro Federal escribió a la Comisión Electoral informando de que el congreso del partido se había hecho sobre la base de la participación de militantes registrados y no de militantes en general. El escrito hace referencia a la legislación sobre partidos políticos de Rusia, que establece la igualdad de derechos de participación en las actividades del partido para todos sus miembros. Se argumenta que el partido no podía hacer una distinción entre militantes registrados y otros miembros del partido con el propósito de participar en sus actividades internas. Por tanto, se habría quebrantado la legislación aplicable.

El 8 de septiembre de 2006 la Comisión Electoral acudió al Tribunal Supremo de la República de Karelia para anular su propia decisión, por la cual se había registrado la lista del partido para las elecciones regionales ya que había nuevos hechos que podían suponer una violación de la legislación aplicable. Se parte de la base de que ya en junio el Servicio de Registro Federal había advertido al partido Yabloko de que una diferenciación entre militantes registrados y otros miembros del partido en las sesiones para elegir a sus candidatos podía suponer un quebrantamiento de las normas aplicables. Finalmente, el 15 de septiembre de 2006, el Tribunal Supremo de Karelia anula las decisiones por las cuales se había registrado la lista de candidatos del partido porque únicamente habían participado en la nominación los militantes registrados, quebrantando así la legislación sobre elecciones y partidos políticos. Concretamente, como se reproduce en la sentencia que se analiza, la decisión del Tribunal Supremo arguye que esta participación de la minoría de los miembros del partido regional en el proceso de nominación había frustrado "la voluntad de la mayoría» de la siguiente manera: 
[...] la sección 8.4 de la ley de partidos estatal dice que los partidos deben proveer una igualdad de oportunidades para la representación del partido, en listas electorales u otros cargos [...]. La sección 23.4 de esa misma norma determina que los miembros de un partido participan en su funcionamiento, tienen derechos y obligaciones en línea con sus estatutos [...] y reciben información sobre las actividades del partido [...]. Sin embargo, este derecho, en relación con los estatutos del partido Yabloko, se reserva a un número limitado de miembros - los militantes registrados o miembros registrados ${ }^{2}$ —, lo cual torna en una vulneración del principio de igualdad de los miembros del partido contenida en la sección 8.1 de la ley de partidos políticos.

A lo anterior añade otra consideración importante, en relación con lo que se analiza en el presente trabajo: «[...] un régimen democrático está caracterizado por la amplia participación del pueblo en la formación de los órganos de la autoridad estatal y por el amplio abanico de derechos políticos y libertades de los ciudadanos [...]. Uno puede imaginar que estos mismos elementos deben aparecer en las actividades de cualquier partido político». Por último, alude a un pronunciamiento de una sentencia del Tribunal Constitucional de la Federación Rusa de 8 de noviembre de 1998 en la que se dice que «las elecciones son un medio para determinar la voluntad del pueblo y formar los órganos legítimos correspondientes a la autoridad del Estado y el gobierno local [...] basadas en la voluntad de la mayoría de los votantes que participan en la elección [...]». Según el Tribunal Supremo, «este principio se aplica con igual medida al nombramiento de listas de candidatos, ya que las bases para formar los cuerpos representativos son los (candidatos) nombrados por los partidos políticos».

El Tribunal Supremo de Karelia rechazó el argumento del partido que alegaba que la legislación aplicable constituía una interferencia con su organización interna. Esta decisión fue recurrida ante el Tribunal Supremo de la Federación Rusa, que la rechazó con un razonamiento muy similar. Todo lo anterior tuvo como consecuencia que la lista de candidatos del partido no se pudo presentar a las elecciones regionales de la República de Karelia.

\section{ARGUMENTOS DE LAS PARTES, FUNDAMENTOS DE DERECHO Y FALLO DEL TRIBUNAL}

Los denunciantes (la rama de Karelia del partido Yabloko y tres nacionales rusos miembros del partido) argumentan que se ha violado el art. 3 del

2 Las cursivas son nuestras. 
Protocolo número 1 (en adelante, art. 3) del Convenio Europeo de Derechos Humanos (en adelante, CEDH), que dispone lo siguiente: «Las Altas Partes Contratantes se comprometen a organizar, a intervalos razonables, elecciones libres con escrutinio secreto, en condiciones que garanticen la libre expresión de la opinión del pueblo en la elección del cuerpo legislativo".

La anulación ordenada, según los denunciantes, habría frustrado su libertad de expresión y de opinión y se habría producido un quebrantamiento del derecho a unas elecciones libres.

También alegan que no se ha contravenido la legislación aplicable, dado que está garantizado por los estatutos del partido el derecho de todos los miembros a inscribirse como militante registrado. Este sería un simple procedimiento que no crea una distinción sustantiva entre los miembros del partido.

En resumen, argumentan que la cancelación del registro de la lista de candidatos del partido está fuera del margen de apreciación nacional en materia electoral y que, además, se habría hecho en favor del partido de gobierno según los sondeos previos a las elecciones regionales.

Por su parte, el Gobierno alega que la anulación de la lista se ha realizado por un Tribunal independiente, basándose en serias infracciones de la legislación electoral por el partido denunciante, que ya se han comentado en el apartado anterior.

También hace referencia a los Lineamientos sobre la regulación de partidos politicos ${ }^{3}$ y al Informe sobre la participación de los partidos políticos en las eleccio$n e s^{4}$ de la Comisión de Venecia. Según el Gobierno, estos documentos afirman que los principios necesarios para una sociedad democrática guían el procedimiento para registrar partidos políticos y que la legislación sobre la nominación de candidatos dentro de los partidos debe respetar los principios democráticos. Sin embargo, la parte demandada se olvida de que el segundo de los documentos también sostiene que los procedimientos internos de los partidos para la toma de decisiones han de estar presididos por el principio de autogobierno (párrafo 17). Como se verá a continuación, el Tribunal Europeo de Derechos Humanos también se sujeta en documentos de la Comisión de Venecia para emitir su decisión.

La valoración del Tribunal Europeo comienza haciendo una referencia a que el art. 3 incluye el derecho a votar y presentarse a las elecciones, en las cuales los partidos han de tener una oportunidad razonable para presentar sus

3 CDL-AD(2004)007rev. Disponible en: https://bit.ly/2Q87LFX. Todas las referencias web de la Comisión de Venecia se han consultado con fecha 11 de marzo de 2019.

4 CDL-AD(2006)025. Disponible en: https://bit.ly/33GoPqz. 
propios candidatos. En otros pronunciamientos, para examinar si ha habido o no cumplimiento por parte del Estado de dicho precepto, se ha valorado la existencia de arbitrariedad o falta de proporcionalidad y si la restricción interfirió la libertad de expresión ${ }^{5}$; y, en lo que al presente caso afecta, se ha interpretado que el derecho a poder presentarse a unas elecciones es inherente al concepto de una verdadera democracia ${ }^{6}$.

Efectivamente, sobre el margen de apreciación nacional al que hacen alusión los denunciantes, el Tribunal fija dos criterios: que existan arbitrariedades o ausencia de proporcionalidad y que la restricción haya interferido con la libertad de expresión, lo que quiere decir que las elecciones no pueden desarrollarse bajo ninguna forma de presión en la opción entre uno o más candidatos, ni que el elector debe estar inducido a votar a uno u otro partido político. El Tribunal reitera que la noción de derecho individual que se engloba en el art. 3, en este caso, es aplicable a los partidos, los cuales presentan una lista en orden a participar en las elecciones. Además, observa que, si se tiene en cuenta el papel que juegan los partidos políticos en nuestra democracia, cualquier medida que afecte a su libertad de asociación, consecuentemente, afecta a la democracia del Estado concernido.

Entrando ya en la aplicación del derecho al caso presente, el Tribunal llega a la conclusión de que la decisión por la cual se anula el registro de la lista del partido Yabloko constituye una restricción de los derechos garantizados por el art. 3. Se argumenta, en primer lugar, que el Tribunal Supremo de Karelia no podía apoyarse directamente en ninguna disposición de la legislación nacional porque no regula los procedimientos internos de los partidos, sino que aplicó los principios generales de la legislación electoral a un procedimiento interno del partido que confería el derecho a participar en la selección de los candidatos a los miembros que habían decidido registrarse como militantes.

Es importante señalar que el Tribunal dice expresamente que la interpretación que hacen los tribunales rusos afecta directamente a la organización interna del partido y que interfiere con su autonomía. Si se tiene en cuenta el art. 11 del Convenio Europeo de Derechos Humanos - libertad de reunión y asociación-, el Estado no debe interferir de manera abusiva en los asuntos internos de las asociaciones, sino que deben ser estas las que determinen la manera en la que organizan sus congresos y conferencias, a juicio del Tribunal.

5 Casos Mathieu-Mohin y Clerfayt. c. Bélgica, de 2 de marzo de 1987, y Zdanoka c. Letonia, de 10 de marzo de 2006.

6 Caso Podkolzina c. Letonia, de 9 de abril de 2002. 
En este sentido, el Tribunal ha señalado el importante papel que desempeñan en un régimen democrático los partidos políticos, que disfrutan de las libertades consagradas en el art. 11 del Convenio. Por eso ha interpretado que las restricciones que se puedan realizar a este precepto, en lo respectivo a partidos políticos, se han de interpretar de manera restrictiva. Los Estados, en este apartado, cuentan con un margen de apreciación más limitado7.

Concretamente, destacan numerosas sentencias condenatorias a Turquía por disolución de un partido político que defendía una solución política al problema kurdo. En ellas se alude a que forma parte de la esencia de la democracia que un partido pueda proponer soluciones políticas a un problema concreto, siempre que se lleve a cabo mediante los cauces democráticos establecidos; aunque tales soluciones mantengan que es necesario modificar, por ejemplo, la organización territorial del Estado que esté vigente en un momento concreto o, en general, que choquen con las convicciones dominantes en la sociedad ${ }^{8}$. El límite es que ello sea defendido a través de medios democráticos 9 . Este mismo criterio - el límite de los procedimientos democráticos en la defensa de sus propuestas - también se encuentra presente en la refutación a registrar partidos políticos ${ }^{10}$.

Es decir, como resume Bilbao Ubillos (2014: 512, 523 y 524), en estos casos el Tribunal aplica el test habitual de proporcionalidad, que «sólo se supera si se cumplen sucesivamente las exigencias de idoneidad, necesidad de la medida en una sociedad democrática y proporcionalidad en relación con los objetivos indicados». Pero, más concretamente, en relación con el art. 11, se requiere «una interpretación estricta, de modo que sólo razones convincentes e imperativas pueden justificar eventuales restricciones». Por supuesto que la libertad para fundar una asociación, y, por tanto, un partido político, es algo inherente a esta disposición, y «los Estados disponen ciertamente de un derecho a comprobar si el objetivo y las actividades de una asociación se ajustan a la legalidad, pero deben usar esta facultad de una manera compatible con las

7 Caso Refah Partisi (Partido del Bienestar) y otros c. Turquía, de 13 de febrero de 2003.

8 Casos Partido Comunista Unido y otros c. Turquía, de 30 de enero de 1998; Partido Socialista y otros c. Turquía, de 25 de mayo de 1998; Partido de la Libertad y la Democracia (ÖZDEP) C. Turquia, de 8 de diciembre de 1999; Yazar, Karatas, Aksoy y Partido de los Trabajadores (HEP) c. Turquí, de 9 de abril de 2002; HADEP y Demir c. Turquía, de 14 de diciembre de 2010, o Partido por una Sociedad Democrática (DTP) y otros c. Turquia, de 12 de enero de 2016.

9 Casos Herri Batasuna y Batasuna c. España, de 30 de junio de 2009, o Vona c. Hungría, de 9 de julio de 2013.

10 Caso Linkov c. República Checa, de 7 de diciembre de 2006. 
obligaciones derivadas del Convenio bajo la reserva del riguroso control que ejercen en último término sus órganos de control».

La pregunta que deviene inmediatamente a continuación es cuáles son los límites al derecho de autoorganización interna de los partidos políticos. Y, a su vez, cuáles son los límites del Estado a la hora de restringir este derecho de autoorganización de los partidos.

El Tribunal ya ha tenido ocasión de pronunciarse al respecto en otros lugares. Ha dicho que las relaciones internas en una asociación quedan fuera de la protección del art. 11, que garantiza la autonomía normativa y organizativa de las asociaciones ${ }^{11}$; y que las autoridades estatales no han de intervenir para exigir que una asociación respete sus propios estatutos, sino que es la propia asociación la que ha de definir la forma que tiene de organizarse y es la encargada de asegurar el cumplimiento de sus propias normas internas ${ }^{12}$.

Aunque la sentencia también haga referencia a otros problemas, como la seguridad jurídica (párrafo 76) o la igualdad (párrafo 91), en cuanto a lo que interesa en este trabajo - la exigencia de democracia interna de los partidos políticos y su derecho de autoorganización-, es importante señalar que el párrafo 79 de la sentencia hace mención a varios documentos elaborados por la Comisión de Venecia ${ }^{13}$. Esta reconoce una cierta dicotomía entre los principios

11 Caso Cheall c. Reino Unido, de 13 de mayo de 1985.

12 Caso Partido Republicano de Rusia c. Rusia, de 12 de abril de 2011.

13 Esta institución surge gracias a Antonio La Pérgola en enero de 1990, quien fuera entonces ministro de Asuntos Exteriores de Italia. En la primera conferencia participaron los miembros del Consejo de Europa y observadores de Europa Central y del Este, con el objetivo de ayudar a estos países en sus transiciones democráticas tras la caída del bloque socialista. Tras esta reunión, la Comisión se integró en el Consejo de Europa. Sus principales objetivos se establecen en el art. 1.1 de su Estatuto: fortalecer el conocimiento de los sistemas legales de los Estados miembros, con la intención de aproximarlos; promover el Estado de derecho y la democracia, y examinar los problemas suscitados por el funcionamiento de las instituciones democráticas, su fortalecimiento y desarrollo.

La Comisión trabaja en tres grandes áreas: instituciones democráticas y derechos fundamentales, justicia constitucional y elecciones, referéndums y partidos políticos. En este último caso, que es lo que más afecta a la sentencia que se está analizando, el objetivo de la Comisión es "ofrecer una visión general de la doctrina en un ámbito concreto y servir de referencia para el poder constituyente y el legislador ordinario» (Craig, 2017: 85). Biglino Campos (2018) ha resaltado la importante labor de la Comisión en su contribución en la elaboración de un patrimonio constitucional común. Otros autores, como Craig, prefieren hablar de órdenes legales internacionales, entendidos estos como «un conjunto de normas jurídicas formalizadas y 
de autonomía de los partidos y el de la exigencia de democracia interna, conforme al Informe sobre el método de nominación de candidatos en los partidos ${ }^{14}$. Dicho texto se refiere a que uno de los límites del derecho de autoorganización de los partidos es que deben respetar los requisitos democráticos para la toma de decisiones, dado que son asociaciones esenciales para el desarrollo de la participación política (párrafo 5). A su vez, diferencia entre aquellos países que adoptan una visión más liberal de la democracia, donde se enfatiza más la autonomía de los partidos, y otros sistemas que tienen un concepto de democracia que reconoce a los partidos como instrumentos fundamentales para la participación política, en los que la regulación de estos se desarrollaría más (párrafo 6). En un escenario donde la Constitución no mencionase a los partidos (como la rusa, cuyo art. 13 solo se refiere a que se reconoce el pluralismo político y el pluripartidismo), el legislador está abierto a su regulación con una mayor amplitud que en aquellos países donde no lo está, pero siempre sujeto al principio de proporcionalidad (párrafo 16). En el caso que nos acontece, el Tribunal no entra en el fondo de la regulación de los partidos rusa, sino que entiende que la decisión tomada por las autoridades rusas ha ido más allá de lo estipulado en el art. 3, sin llegar a valorar la legislación partidaria.

El Tribunal también hace referencia a que los Lineamientos sobre la regulación de los partidos políticos ${ }^{15}$ establecen el límite para la interferencia

organizaciones y actores asociados que, basándose en criterios de autoridad, ordenan las interpretaciones y prácticas jurídicas en diversas jurisdicciones nacionales» (2017: 90). A esto también ha contribuido el Convenio Europeo de Derechos Humanos, cuyo objetivo ha sido "alcanzar una concepción de los derechos sustancialmente igual o equivalente» (García Roca, 2018: 27) entre los europeos.

La Comisión de Venecia elabora informes, códigos y directrices que sirven para «enfrentarse a casos difíciles o tomar postura en asuntos que dividen a la opinión pública de los Estados [...] para mantener una solución conforme al patrimonio constitucional común» (Biglino Campos, 2018: 6). Además, puede sugerir maneras de solventar problemas que sucedan en los países que conforman el Consejo de Europa (Craig, 2017: 92). Sin embargo, los códigos y directrices de la Comisión de Venecia, para que tengan eficacia jurídica plena, han de ser concretados por los Estados; pero este carácter de soft law no les priva de efectividad en el ámbito interno ni en el supranacional. Serían una especie de "principios rectores" que se han de tener en cuenta, especialmente, porque el Tribunal Europeo de Derechos Humanos los utiliza para observar si los Estados han cumplido con el art. 3 del Protocolo núm. 1 del Convenio Europeo de Derechos Humanos (Biglino Campos, 2018: 7-8). Esto último es exactamente lo que ha sucedido en el presente caso.

14 CDL-AD(2015)020. Disponible en: https://bit.ly/2NEBFzW.

15 CDL-AD(2010)24. Disponible en: https://bit.ly/2CES2Gd. 
del Estado en las actividades internas de los partidos en establecer como requisito que estos sean "transparentes con respecto a su toma de decisiones y para que busquen las aportaciones de los miembros cuando se determine la constitución y los candidatos del partido» (párrafo 98 de los Lineamientos). Hay que precisar que este documento comienza definiendo a los partidos como «medios fundamentales para el desarrollo de la democracia representativa, y por medio de los cuales los ciudadanos participan en su gobierno", con el objetivo de "ofrecer una visión general acerca de cuestiones relativas al desarrollo y adopción de legislación referente a los partidos políticos en las democracias» (párrafos 3 y 4 ). Debido a ese importante papel que desarrollan, la Comisión de Venecia reconoce que los Estados pueden entrar a regular su funcionamiento para asegurar el respeto de los derechos fundamentales de sus miembros, pero siempre sin que dicha legislación obstruya su libertad de asociación (párrafo 6). De esta forma, establece como límite a la autoorganización de los partidos, como recuerda el Tribunal, la transparencia con respecto a la nominación de candidatos y la toma de decisiones (párrafos 98 y 113); a lo que ańade que, en todo caso, las regulaciones sobre la nominación de candidatos deben garantizar el derecho del ciudadano a ser candidato en las elecciones (párrafo 126).

De los anteriores documentos, a juicio del Tribunal, se desprende que la Comisión de Venecia reconoce que tanto la toma de decisiones de manera directa como la forma indirecta son admisibles para cumplir con el requisito del derecho de participación de los miembros de un partido político en cuestiones de organización interna, y, en lo que afecta a este caso, la nominación de candidatos a elecciones, siempre que se garantice alguna forma de representación de los miembros de base del partido, una responsabilidad y rendición de cuentas hacia ellos y que el procedimiento sea transparente. En cuanto a la diferenciación entre militantes registrados y otro tipo de miembros del partido, se hace mención al Código de buenas prácticas en el ámbito de partidos políti$\cos ^{16}$, cuyo párrafo 24 dice:

[...] no es inusual que los partidos establezcan diferentes formas de participación en sus actividades por parte de los individuos tales como miembros, simpatizantes reconocidos, colaboradores, quienes participan en campańas (campaigners), etc. Estos estatutos marcan diferentes umbrales de compromiso personal. Por lo tanto, para identificar el tipo de compromiso y respetar las decisiones personales, una buena práctica es que los estatutos del partido definan claramente los diferentes derechos y deberes de cada situación.

16 CDL-AD(2009)021. Disponible en: https://bit.ly/34TcBe9. 
Cualquier persona debe poder definir libremente la forma de su relación personal con un partido.

Esto es lo que habrían hecho los estatutos del partido Yabloko. Además, este Código también hace referencia a otro límite en la autoorganización de los partidos: la necesaria rendición de cuentas y la responsabilidad interna y externa de sus dirigentes, y, de nuevo, la transparencia (párrafo 28); a la vez que reconoce que los partidos pueden decidir internamente el método de elección de sus candidatos y dirigentes, ya sea de manera directa o indirecta (párrafos 35 y 36).

Llama la atención que ni el Tribunal ni ninguna de las partes hagan mención a otro documento importante de la Comisión de Venecia en cuanto a lo que acontece en el caso: el Código de buenas prácticas en materia electoral ${ }^{17}$. Aquí se dice que el Estado ha de mostrarse imparcial con los partidos y garantizar la igualdad de oportunidades (párrafo 18). Según los hechos, parece que esta disposición no fue cumplida por Rusia.

El Tribunal finaliza diciendo que la decisión de anular la lista de candidatos del partido por una razón formalista (el partido había registrado dos versiones diferentes de sus estatutos con la aceptación de la Autoridad Federal de Registros) es desproporcionada.

Por todo lo anterior, concluye que se ha interferido por parte de la Federación Rusa de manera desproporcionada en la organización interna del partido, la cual sigue los principios de transparencia y de representación, habiéndose producido, de esta manera, una inhabilitación para participar en las elecciones regionales. En estas circunstancias, el Tribunal entiende que se ha violado el art. 3 del Protocolo número 1 del Convenio Europeo de Derechos Humanos.

Para llegar a esta conclusión, el Tribunal incluye como canon de control del Convenio los informes de la Comisión de Venecia en cuanto a lo que se refiere al art. 3 del Protocolo número 1. Se podría decir, entonces, que estos textos no son meramente soft law, sino que se constituyen como verdadero parámetro de convencionalidad que los Estados han de tener presente a la hora de resolver controversias y desarrollar su legislación en materia electoral y de partidos políticos. En el presente caso, los usa como fuente de interpretación para resolver la contradicción existente entre el derecho de autoorganización de los partidos y la exigencia de democracia interna debido a su importante papel en la formación de la voluntad del Estado.

17 CDL-AD(2002) 023 rev. Disponible en: https://bit.ly/32IXJgW. 


\section{LA IMPORTANCIA DE LA DECISIÓN EN EL DEBATE SOBRE LA INTRODUCCIÓN DE PRIMARIAS EN LOS PARTIDOS POLIITICOS EN ESPAÑA}

Actualmente todos los partidos estatales con representación parlamentaria, menos Vox, han elegido de manera directa a sus líderes y, a excepción del Partido Popular (que únicamente lo dispuso para la elección de su Presidencia nacional), también regulan en sus estatutos las primarias para la designación de candidatos ${ }^{18}$.

En este momento está en debate que la designación por primarias de los candidatos de los partidos se realice de manera obligada porque así lo estipule la ley. Ahora los procesos internos de designación de candidatos no son controlables por los tribunales ordinarios, debido a que se consideran un ámbito interno de los partidos. Así lo ha confirmado la sentencia del Tribunal Supremo 3861/2014, de 25 de septiembre, en la que se estipula que la Constitución impone un funcionamiento democrático de los partidos, pero no cómo estas formaciones han de designar a sus candidatos.

Efectivamente, el art. $6 \mathrm{CE}$ establece un límite al derecho de autoorganización de los partidos: la exigencia de democracia interna. Es decir, en los partidos hay una nueva dimensión que se le ańade al derecho de asociación, en diferencia con otras organizaciones: los derechos de participación democrática interna de los afiliados (Flores Giménez, 1998: 64). Pero lo que no dice la Constitución, ni lo impone, es un tipo concreto de democracia para aquellos. Así lo ha declarado el Tribunal Constitucional en su sentencia 56/1995 al afirmar que dicho mandato constitucional se puede cumplir con una gran variedad de modelos posibles, sin que sea obligatorio el uso de primarias, siempre que se respete el principio de participación de los afiliados. En cualquier caso, la democracia interna en el interior de los partidos siempre tiene como límite a su derecho de autoorganización el reconocimiento al afiliado de todos sus derechos fundamentales (Vírgala Foruria, 2000: 86) y el control de sus garantías materiales (García Guerrero, 1996: 52) ${ }^{19}$.

18 Véanse el art. 3 del Reglamento para el XIX Congreso Nacional Extraordinario del Partido Popular, art. 44.3 de los Estatutos del PSOE, art. 5 del Documento Organizativo de Podemos, art. 41 de los Estatutos de Ciudadanos y art. 75 de los Estatutos de IU.

19 Sobre esta cuestión el Tribunal Constitucional se ha pronunciado en la Sentencia $218 / 1988$ y en la más reciente 226/2016, en lo que parece haberse dado una evolución de su doctrina. El Alto Tribunal declaró en la primera de ellas que «el régimen de las asociaciones se determinará por los propios Estatutos y por los acuerdos válidamente 
Empero lo anterior, la crisis de la representación y de los partidos ha conllevado que se propongan medidas de regeneración, como es la de regular las primarias por vía legal y que estas sean una obligación para los partidos ${ }^{20}$. Esta posibilidad es una cuestión discutida en la doctrina, en la que encontramos diversas opiniones. Quienes sostienen una postura a favor argumentan que el límite del art. $6 \mathrm{CE}$ al derecho de autoorganización de los partidos permite que se ofrezca "una cobertura más que suficiente» (Sánchez Muñoz, 2015: 421) para la intervención del legislador. Además, «los parlamentarios no son realmente escogidos por los ciudadanos, sino por los partidos, los cuales posteriormente someten su decisión a la ratificación del electorado» (ibid.: 417); que la designación de un candidato «no es una mera cuestión interna de los partidos; incide sobre el ejercicio del derecho de acceso de cualquier ciudadano en condiciones de igualdad a los cargos públicos» (Garrido López, 2015: 195), o que el ciudadano solo es candidato en potencia y son los partidos los

adoptados por la Asamblea General y órganos directivos competentes», pero que «la actividad de las asociaciones no forma naturalmente una zona exenta del control judicial». El Tribunal, sin embargo, ańade que, cuando los Estatutos no sean contrarios a la Constitución o la ley, lo único que podrá hacer es no valorar la conducta del socio, sino «comprobar si existió una base razonable para que los órganos de las asociaciones tomasen la correspondiente decisión» (FJ 1). Es decir, que «el derecho de los socios como miembros de la asociación consiste en el derecho a que se cumplan los estatutos, siempre que estos sean conformes a la Constitución y a las leyes. [...] Dejar la valoración de una conducta en un supuesto determinado [...] al juicio del órgano sobre del gobierno de la Asociación [...] entra en el contenido del derecho de asociación como elemento integrante de su derecho de autoorganización» (FJ 2). La STC 226/2016 se refiere a la decisión de un partido político y, aunque esta sea una especial modalidad de asociación, de manera general el máximo intérprete de la Constitución ha interpretado aquí que su control jurisdiccional "puede adentrarse en la ponderación de la conformidad constitucional de ciertas decisiones de la asociación que impliquen una injerencia en un derecho fundamental» (FJ 8). Es decir, que con esta nueva doctrina, a diferencia de lo que dijo en la STC 218/1988, el Tribunal Constitucional parece entender que, cuando se trata de una posible vulneración de un derecho fundamental ad intra de una asociación debido a la adopción de un acuerdo por un órgano de gobierno, puede entrar a valorar la decisión del órgano sin que ello sea contrario a su derecho de autoorganización.

20 Merece la pena destacar la proposición de ley del Grupo Parlamentario Ciudadanos en las Cortes de Castilla y León para la reforma de la Ley 3/1987, de 30 de marzo, Electoral de Castilla y León. Boletín Oficial de las Cortes de Castilla y León, núm. 85, 19 de febrero de 2016, pp. 11121 y ss. Al final de la legislatura esta proposición estaba en fase de debate en Comisión y no se concluyeron los trabajos para su último debate en Pleno. 
que realmente concretan a los elegibles (Rodríguez Díaz, 1990: 106). A mayor abundamiento, la selección del candidato tiene importantes consecuencias internas y externas, lo que induce a pensar que dicho proceso «debería venir regulado por ley» (Pérez-Moneo Agapito, 2012: 175-176). A esto se le ha de añadir que en España «las circunscripciones plurinominales y las listas cerradas y bloqueadas provocan que la inclusión en una candidatura no dependa tanto de los resultados que cabe esperar del candidato como de las relaciones que este mantenga dentro de su propia formación» (Biglino Campos, 2015: 204). Ya Duverger advirtió de que el sufragio indirecto «es un medio admirable de prescindir de la democracia» (1957: 170). Por tanto, parecería que las primarias podrían ser un buen método para mejorar la democracia de los partidos y la democracia representativa en general si tenemos en cuenta que «los partidos políticos operan como un instrumento de control de la oferta electoral mediante el que una élite política sustituye a la sociedad en la definición de un aspecto esencial del proceso de legitimación democrática y la fuerza a optar por alternativas cerradas» (Pérez Royo, 1994).

Quienes sostienen esta postura más proclive se apoyan en la jurisprudencia del Tribunal Constitucional en relación con la exigencia legislativa de cuotas electorales de género en las candidaturas. La STC 12/2008 avaló que, efectivamente, el legislador pudiera introducir esta exigencia al considerar que dicha medida se proyecta sobre un ámbito externo y no interno en la vida de los partidos; por lo que, en este ámbito —el externo—, «el legislador puede imponer condiciones para su presentación, orientadas a la consecución de fines legítimos» (Pajares Montolío, 2016: 163) y «la regulación legal de las elecciones primarias es, por tanto, constitucionalmente posible» (Garrido López, 2015: 196).

Pero las primarias también pueden ocasionar problemas. Entre otros, provocar fuertes confrontaciones en el seno de los partidos o legitimar decisiones adoptadas de antemano por los dirigentes (Flores Giménez, 1998: 229), lo que traslada la responsabilidad de estos hacia los inscritos en el partido, y la dificultad para adaptarlas en un sistema parlamentario y la deriva presidencialista que puede conllevar, además de la colisión con posibles futuros acuerdos en sede parlamentaria para elegir al presidente del Gobierno o de una comunidad autónoma (Pajares Montolío, 2016: 188, Pérez-Moneo Agapito, 2015: 228 y Dueñas Castrillo, 2017: 27-28). También puede suceder que se dé un mayor o excesivo protagonismo a los medios de comunicación en estos procesos internos que los conviertan en "debates presididos por la lógica mediática» (González Rodríguez, 2017: 619) o en «auténticos plebiscitos personales que otorgan o quitan la confianza a los líderes de las formaciones políticas» (Salazar Benítez, 2000: 143). Podrían también conllevar el efecto contrario: un gran poder del 
líder del partido que impide que las minorías se puedan manifestar, debido a su legitimación directa por su elección en primarias, algo que se ha podido observar a la hora de confeccionar las listas en las últimas elecciones generales ${ }^{21}$ y que también se había apuntado anteriormente por la doctrina, debido a que el nuestro es un sistema electoral proporcional y no mayoritario, por lo que «el ganador de las primarias encabeza una lista bloqueada y cerrada y pueden surgir dificultades sobre si la confección de la misma corresponde a éste o al partido» (García Guerrero, 2007: 152). Se ha llegado a afirmar por algún autor que, incluso, «si las primarias se generalizasen, cambiaría el modelo político impuesto en la transición política y en la Constitución» (Boix, 1998: 38). Esta postura se podría resumir argumentando que «el juego combinado de los artículos 6 y 23.1 de nuestra Norma fundamental obliga a entender que la exigencia constitucional de democracia interna se concreta, también, en el derecho de participación de los afiliados en la designación de quienes habrán de integrar las listas electorales de los partidos políticos», pero alcanzar el fin constitucional de garantizar el carácter democrático de la elaboración de las candidaturas puede hacerse «sin intervenir de modo tan restrictivo sobre la libertad asociativa» (Saiz Arnaiz, 2000-2001: 187 y 191).

La cuestión que se puede formular a continuación, a raíz de la solución adoptada en la sentencia que se analiza, es si la adopción de primarias por vía legislativa podría vulnerar el art. 3 del Protocolo número 1 del Convenio Europeo de Derechos Humanos, al ser una medida desproporcionada que atenta contra la libre organización de los partidos.

Ya se ha señalado que el Código de buenas prácticas en el ámbito de los partidos políticos exige únicamente que los candidatos deben ser elegidos democráticamente, ya sea de manera directa o indirecta (párrafo 36); mientras que los Lineamientos sobre la regulación de los partidos disponen que la selección ha de hacerse con criterios transparentes y claros, pero en ningún caso se habla de exigencia primarias (párrafo 113). Por su parte, el Informe sobre el método de nominación de candidatos en los partidos politicos alude a que los partidos son libres para establecer su propia organización para elegir a sus candidatos (párrafo 5) y que la interferencia estatal en la selección de candidatos puede poner en peligro el pluralismo político (párrafo 81).

En la presente sentencia, el Tribunal declara que las autoridades estatales no deben interferir en los asuntos internos de las asociaciones, sino que deben ser estas las que determinen la manera en la que se organizan sus congresos y conferencias (párrafo 77) y que la toma de decisiones directas e indirectas en

${ }^{21}$ Ello ha sido criticado por la opinión pública. Véanse https://bit.ly/350W3Bf y https:// bit.ly/33Gt9Gj. 
el seno de los partidos políticos (como puede ser la selección de candidatos) son admisibles siempre que se garantice la exigencia de responsabilidad de los elegidos, su rendición de cuentas, y exista transparencia en el proceso de selección (párrafo 79).

Por tanto, se podría decir que la exigencia obligatoria de primarias podría llegar a vulnerar el art. 3. Pero, como recuerda el Tribunal, y siguiendo a Biglino Campos, se le podría exigir al legislador algo más sencillo: que impusiera «en los procesos de selección interna de los candidatos los requisitos inherentes al principio democrático, esto es, que el procedimiento sea público y que se lleve a cabo con pleno respeto al derecho de participación, la igualdad y la libertad de expresión de los afiliados» (2017: 502), algo que el propio Tribunal ha declarado como límite a la autonomía de los partidos.

\section{CONCLUSIONES}

La sentencia analizada demuestra su importancia en tanto en cuanto el Tribunal Europeo de Derechos Humanos establece aquí los límites del Estado en la regulación de los partidos políticos y también de estos en lo que a su derecho de autoorganización se refiere. El propio Tribunal declara la importancia que los partidos desempeñan en el actual modelo de democracia, por lo que el Estado puede entrar a regularlos, a diferencia de otras asociaciones, pero sin interferir de manera abusiva en sus asuntos internos.

El papel que juega la Comisión de Venecia en la resolución de este caso es fundamental. Sus informes pasan de ser mero soft law a convertirse en fuente de interpretación para el Tribunal Europeo de Derechos Humanos, que le sirve para observar si ha existido o no incumplimiento por parte de Rusia del art. 3 del Protocolo número 1 del Convenio Europeo de Derechos Humanos. Es cierto que estos textos no tienen eficacia directa interna en los Estados que forman parte de la Comisión, pero si atendemos a cómo se han usado por el Alto Tribunal Europeo en este asunto, los Estados del Consejo de Europa deben tenerlos muy presentes a la hora de regular cuestiones relacionadas con el ámbito electoral y los partidos políticos; al igual que sus tribunales también deben tomarlos en cuenta en la resolución de los casos internos de cada país.

Por último, este asunto es especialmente relevante en lo referente al debate actual en España sobre la posible introducción por vía legislativa de las primarias para la designación de candidatos en los partidos políticos. Los límites que ha establecido el Tribunal en este caso en la autoorganización de los partidos es que han de respetar los principios de transparencia y participación. Si así lo hacen, están cumpliendo con el requisito de democracia interna. El Tribunal 
no parece imponer un modelo de democracia para los partidos, sino que reconoce que tanto la toma de decisiones de manera directa como la forma indirecta son válidas. Aunque sea un caso concreto, en esta resolución podría estar dándose la razón al sector doctrinal que opina que las primarias vulnerarían el derecho de autoorganización de los partidos, en el sentido de que establecer un concreto modelo de democracia para la nominación de candidatos por parte del legislador podría ser contrario al art. 3 del Protocolo número 1 del Convenio Europeo. Sin embargo, podría entenderse que esta forma de nominación de candidatos podría regularse por la vía del art. $23 \mathrm{CE}$ - derecho participación política-y no tanto por la vía del art. $22 \mathrm{CE}$ - derecho de asociación-. Lo que sí que podría hacer el Estado es establecer una regulación que impusiera que los procesos de selección de candidatos se lleven a cabo de manera pública, transparente y con respeto al principio de participación. Si así sucediera, tales procesos podrían considerarse como una fase previa del procedimiento electoral, con las ventajas en materia garantista que ello conllevaría.

\section{Bibliografía}

Biglino Campos, P. (2015). Intervención del legislador y selección de candidatos por los partidos políticos: una perspectiva comparada. Teoría y Realidad Constitucional, 35, 203223. Disponible en: https://doi.org/10.5944/trc.35.2015.14918.

(2017). Crisis de la representación, legitimidad de ejercicio y formas de responsabilidad. Revista de Derecho Politico, 100, 481-511. Disponible en: https://doi.org/10.5944/ rdp.100.2017.20707.

- (2018). La Comisión de Venecia y el patrimonio constitucional común. Revista General de Derecho Constitucional, 28.

Bilbao Ubillos, J. M. (2014). Las libertades de reunión y asociación: algunas vacilaciones en una trayectoria de firme protección (art. $11 \mathrm{CEDH})$. En J. García Roca y P. Santolaya (coords.). La Europa de los Derechos. El Convenio Europeo de Derechos Humanos (pp. 565-620). Madrid: Centro de Estudios Políticos y Constitucionales.

Blanco Valdés, R. (1990). Los partidos políticos. Madrid: Tecnos.

Boix, C. (1998). Las elecciones primarias en el PSOE: ventajas, ambigüedades y riesgos. Claves de Razón Práctica, 83, 34-38.

Craig, P. (2017). Constitucionalismo transnacional: la contribución de la Comisión de Venecia. Teoría y Realidad Constitucional, 40, 79-109. Disponible en: https://doi. org/10.5944/trc.40.2017.20905.

De Otto Pardo, I. (1985). Defensa de la Constitución y partidos políticos. Madrid: Centro de Estudios Constitucionales.

Dueñas Castrillo, A. I. (2017). La investidura de los presidentes autonómicos y primarias en los partidos políticos: fortalecimiento del presidencialismo parlamentario autonómico. Revista de Estudios Jurídicos, 17. Disponible en: https://doi.org/10.17561/rej.n17.a4. 
Duverger, M. (1957). Los partidos políticos. Ciudad de México: Fondo de Cultura Económica.

Flores Giménez, F. (1998). La democracia interna de los partidos politicos. Madrid: Congreso de los Diputados.

García Guerrero, J. L. (1996). Democracia representativa de partidos y Grupos Parlamentarios. Madrid: Congreso de los Diputados.

— (2007). Escritos sobre partidos políticos (cómo mejorar la democracia). Valencia: Tirant lo Blanch.

García Pelayo, M. (1986). El Estado de partidos. Madrid: Alianza.

García Roca, J. (2018). La transformación del Convenio Europeo de Derechos Humanos. Revista General de Derecho Constitucional, 28.

Garrido López, C. (2015). La exigencia de democracia en los partidos políticos: insuficiencias normativas e iniciativas para concretizarla. En M. Contreras Casado y C. Garrido López (coords.). Interiores del Príncipe Moderno. La democracia en los partidos politicos, entre la necesidad y la dificultad (pp. 161-202). Zaragoza: Comuniter.

González Rodríguez (2017). Crisis de la democracia de partidos y segunda transición. Revista de Derecho Politico, 100, 615-638. Disponible en: https://doi.org/10.5944/rdp.100.2017.20712.

Kelsen, H. (1934). Esencia y valor de la democracia. Barcelona: Labor.

Pajares Montolío, E. (2016). Selección de candidatos y mejora del sistema electoral: consideraciones sobre las elecciones primarias. En J. L. Cascajo Castro y A. Martín de la Vega (coords.). Participación, representación y democracia. XII Congreso de la Asociación de Constitucionalistas de España (pp. 151-192). Valencia: Tirant lo Blanch.

Pérez-Moneo Agapito, M. (2012). La selección de candidatos electorales en los particos. Madrid: Centro de Estudios Políticos y Constitucionales.

— (2015). Elementos y modelos de selección de candidatos electorales en los partidos políticos. En M. Contreras Casad y C. Garrido López (coords.). Interiores del Principe Moderno. La democracia en los partidos políticos, entre la necesidad y la dificultad (pp. 205-232). Zaragoza: Comuniter.

Pérez-Royo, F. J. (1994). La raíz del problema. El País, 17-3-1994.

Rodríguez Díaz, A. (1990). El Estado de partidos y algunas cuestiones de Derecho Electoral. Revista de Derecho Politico, 31, 89-122.

Saiz Arnaiz, A. (2000-2001). Elecciones primarias, representación política y democracia interna en los partidos: entre la ilusión y el escepticismo. Anuario de Derecho Constitucional y Parlamentario, 12-13, 179-202.

Salazar Benítez, O. (2000). Las primarias socialistas: una experiencia de democratización de la selección de candidatos. Teoría y Realidad Constitucional, 6, 136-162.

Sánchez Muñoz, O. (2015). Los partidos y la desafección ciudadana: propuestas desde el campo del Derecho Constitucional. Teoria y Realidad Constitucional, 35, 413-436. Disponible en: https://doi.org/10.5944/trc.35.2015.14925.

Solozábal Echavarría, J. J. (2015). El principio democrático y las instituciones de participación directa replanteados. En A. E. Alcubilla y P. González-Trevijano (dirs.). En pro de la regeneración politica en España (pp. 279-311). Cizur Menor (Navarra): Aranzadi.

Vírgala Fururia, E. (2000). Ejercicio de derechos por los afiliados y control judicial de las sanciones impuestas por los partidos políticos. Teoría y Realidad Constitucional, 6, 83-108. Disponible en: https://doi.org/10.5944/trc.6.2000.6521. 